\title{
Challenges in Utilising Budgets among SMES in the Manufacturing Sector is the Cape Metropole
}

Mwanza PS and Benedict HO*

Department of Business and Management Sciences, Cape Peninsula University of Technology, South Africa

\begin{abstract}
As management accounting tools, budgets are internationally recognised for their role in planning of activities, and efficient allocation of resources in business entities. Preparation and utilisation of budgets for managing businesses is not without challenges. The purpose of this study was to establish the extent of preparation and utilisation of budgets by SMEs in the manufacturing industry in the Cape Metropole, with a focus on identifying the challenges faced by these entities in using these management accounting tools. To this end the study pursued a descriptive research design, collecting data from 108 owners/managers of SMEs in the manufacturing industry in the Cape Metropole. The data was collected through a questionnaire which contained closed questions and Likert-scale questions. Data analysis was conducted using SPSS version 24, and the results were presented through descriptive statistics in the form of percentages, means, standard deviations, graphs and tables. The results of the study show that close to $30 \%$ of SMEs in the manufacturing industry in the Cape Metropole do not prepare budgets at all. Amongst the $70 \%$ who prepare budgets, $67 \%$ face challenges in utilising budgets. Overall, only $23 \%$ of the surveyed SMEs prepare budgets and utilise them without facing challenges.
\end{abstract}

Keywords: Management; Businesses; Budgets; Manufacturing industry

\section{Introduction}

The government of South Africa recognises the critical contribution by SMEs as drivers of job creation and economic growth. Understandably, the government has proactively supported SMEs through its policies, strategies, and agencies [1]. Despite the aforementioned, SMEs are failing with records consistently showing a first-year failure rate of $70 \%$ to $80 \%[2,3]$. Scholarly endeavours towards investigating the causes of failure of SMEs, have revealed that the major causes of SME failure are mainly internal factors [4,5]. According to the latter research findings, SMEs fail owing to, among other causes, a lack of financial control, poor production planning and poor financial management skills within the entities. Lwiki et al. [6] highlight the importance of financial planning and point out that there are many reasons for SME failure, amongst them being a lack of planning. Berry [7] concurs that many entrepreneurs do not plan and control the financial activities of their businesses; hence they do not survive in a competitive market. Bruwer et al. [8] and Olosola and Olowaseun found out that SMEs do not make adequate use of budgets in order to make effective decisions [9].

A budget is a formal expression of plans covering various business activities in quantity and monetary terms for a specific period in the future [9]. While budgets quantify business revenues and expenses, they play a critical role in the achievement of organisational goals Zimmerman [10], Berry [7] advises SME managers to prepare budgets, so as not to overlook overheads, a trap which may lead to poor cash management and subsequent business failure. Budgets have the additional benefit of providing investors and creditors with information to guide the granting of credit to the business. Olusola and Olowaseun [9] observed that if SMEs managers prepare budgets, they are compelled to scan the business environment to identify any foreseeable constraints, and prepare in advance methods of overcoming or avoid these constraints. From the above discussion, effective use of budgets may increase the SME manager's ability to make sound business decisions and thereby achieve growth and sustainability. Hence the problem under study is that there is a perceived lack of utilization of budgets for managing businesses among SMEs in the manufacturing industry in the Cape Metropolis. This lack of utilization of budgets can lead to business failure. The remainder of this paper is structured as follows: The literature review in Section 2 discusses SMEs in the manufacturing industry in South Africa and the importance of utilization of budgets by SMEs in the manufacturing industry. Thereafter the section covers the challenges faced by SME owners/managers when using budgets in managing their businesses. The methodology employed in this study is outlined in Section 3 which is followed by Section 4 on results and discussion of findings. Section 5 closes the paper with a conclusion.

\section{Literature Review}

\section{SMEs in the manufacturing industry}

Manufacturing is transforming raw materials or components into finished goods that meet a customer's expectation or specification [11,12]. Small Enterprises Development Agency (SEDA) [13] Defines manufacturing as a process involving tools and labour which produce goods for use or sale as intermediaries, or as final products, either domestically, or internationally [13]. The Standard Industrial Classification (SIC) classifies major activities in the South African manufacturing industry as agro-processing, metals and engineering, oil and petroleum, chemical, and clothing and textiles [14].

Mthabela [15] reports that the manufacturing industry contributes to the development of other economic areas. Matsoso and Benedict [12] affirm that SMEs contribute to national Gross Domestic Product

*Corresponding author: Benedict HO, Department of Business and Management Sciences, Cape Peninsula University of Technology, South Africa, Tel: 021460 3174; E-mail: BenedictH@cput.ac.za

Recieved November 22, 2017; Accepted January 30, 2018; Published February 06, 2018

Citation: Mwanza PS, Benedict HO (2018) Challenges in Utilising Budgets among SMES in the Manufacturing Sector Is the Cape Metropole. J Entrepren Organiz Manag 7: 222. doi: 10.4172/2169-026X.1000222

Copyright: (c) 2018 Mwanza PS, et al. This is an open-access article distributed under the terms of the Creative Commons Attribution License, which permits unrestricted use, distribution, and reproduction in any medium, provided the original author and source are credited. 
(GDP) by manufacturing goods of value. These entities are vital players in the economic in their role as customers of larger enterprises, particularly of industrial goods, and as producers of domestic goods [15]. Thus SMEs either support other sectors which export products or can substitute imported products. Essentially, SMEs are consumers of raw materials and labour and suppliers of goods and services. As consumers these entities have purchasing power, stimulating economic activities of their suppliers.

In South Africa, $12 \%$ of the formal small enterprises fall under manufacturing, the sector occupies a notable share of the South Africa economy, even though its real terms relative contribution declined from 19 per cent in 1993 to about 17 per cent in 2012 [16].

\section{Importance of budgets to SMEs in the manufacturing industry}

Needles and Crosson [17] group budgets into two broad categories: budget schedules, and budget summaries. Budget schedules include the sales, production, direct materials, direct labour, manufacturing overheads and the selling and administration costs budgets. Worrel [18] explains that budget summaries combine the data from these schedules and other supporting information into projected cash-flow statements, income statements and balance sheet.

The sales budget: Is constructed using information from marketing research and sales personnel who use previous sales experience to forecast [10]. The business environment is constantly changing and SME owners/managers are encouraged to engage in market research so as to improve their businesses or identify new business alternatives $[19,20]$. Equally important in the construction of the sales budgets is historical sales data which is modified to market trends and anticipated changes in economic conditions. SMEs in the manufacturing industry may equally forecast their sales for the budget period ensuring attainable budgeted volumes under the economic conditions and to recognise seasonal variations. As a starting point, SMEs without previous sales records may use Cost-Volume-Profit analysis to work out the number of units which must be sold to in order to pay the fixed costs of the business as illustrated in Drury [21]. The importance of a sales budget to SMEs in the manufacturing industry is also stated by Bruwer et al. [8]. This budget also supplies the basic data for constructing the rest of the budgets needed by the SMEs in the manufacturing industry [10].

The production budget: Ensures that SMEs produce sufficient units to meet sales demand and to maintain economic stock levels [7]. In doing so, SMEs will avoid two pitfalls: overproduction and underproduction. Groover [22] warns that overproduction ties up the much needed working capital of the SME in unproductive inventory. Underproduction, on the other hand results in under stocking of goods for sale [22] which among other things, causes loss of sales coupled with loss of goodwill for SMEs.

The direct materials purchase budget: Direct materials are goods needed to manufacture directly and or indirectly the finished products that will ultimately be sold Zimmerman [10], Drury [21] recommends that figures included in the materials purchases budget should be variable costs only, such as raw materials components and packaging items that enter the work-in-process cycle to produce the final product. By using the direct materials purchase budget, SMEs can minimise the negative effects of raw materials price increases by anticipating the increases and planning for them, additional costs being incurred to source stock at short notice in order to meet demand. Drury [21] underscores that optimum stock-keeping levels of raw materials will minimise the storage and other stock-keeping costs.
The direct labour budget: Calculates the number of labour hours required to produce the units planned in the production budget [22,23]. As stated by Lohr [19], it is important for SMEs to draw up a direct labour budget to determine the need for and the cost of labour. This budget can aid SMEs to anticipate hiring needs, when to schedule overtime, and to lay off staff. Without the direct labour budget, owners/ managers might find that they do not have enough staff to complete the required production within a given time. For the direct labour budget to be useful, it should include not only the components of labour input and the required hours per category of labour [24], but also other labour costs such as UIF and SDL are included in the cost of direct labour [25].

The factory overhead budget: Projects all the manufacturing costs except the direct materials and the direct labour costs [21]. Examples of manufacturing costs are indirect materials, indirect labour, factory utilities and depreciation of factory machinery and equipment [10] Without a factory overhead budget, SMEs in the manufacturing industry may fail to recognise the role of indirect manufacturing costs during the production process [2]. This could result in SMEs undercosting and under-pricing their products [26] which may ultimately lead to business failure.

The selling and administration budget: According to Kaplan and Atkinson [27], the selling and administration budget comprises all the projected non-manufacturing costs of a business. Non-manufacturing costs are incurred when running the operations which support the product or sales-generating activities of a business [2].

For SMEs in the manufacturing industry, non-manufacturing costs include all costs necessary to secure customer orders, placing the finished product in the hands of a customer, wages or salaries for non-factory staff, office rent, and depreciation of office furniture and equipment [19]. Lamentably, DTI, Shaku [2] and Mutanda et al. [25] found that selling and administrative costs are inadequately planned for or even overlooked by SMEs.

The cash budget: Needles and Crosson [17] define cash budget as a projection of the future cash position of the business, detailing the expected cash inflows and outflows. For SMEs, cash inflows include sales revenue, receipts from loan, receipts from debtors, and any proceeds from sale of assets other than trading inventory. Similarly, cash outflows include cash payments necessary to implement the direct materials purchases budget, the direct labour budget, and all the expenses in the manufacturing overheads budget except depreciation. Expenses in the selling and administrative costs budget must be included in the cash budget as recommended by Kirsten and Fourie [26].

SMEs owners/managers should budget for cash requirements for non-routine payments such as tax on profits, insurance and acquisition of non-current assets, as these, if overlooked, are likely to plunge the business into liquidity problems [28]. Acquisition of non-current assets needs to be budgeted for in the cash budget more so by SMEs in the manufacturing industry, in which there is a need for businesses to invest substantially in machinery. According to Bruwer et al. the primary reason for the failure of many SMEs is because of lack of a cash budget [29]. SMEs in the manufacturing industry can benefit significantly by using the cash budget to take pro-active steps to invest any surplus cash in short-term investments. Cash deficiencies can equally be identified in advance and necessary steps taken to ensure that they are made up for through borrowings [26,30].

The master budget: Is the aggregation of all the other budgets 
prepared by a business. It includes the budgeted profit and loss account as well as the budgeted balance sheet [23].

Previous studies $[2,25]$ show that one of the challenges faced by small businesses is lack of funding. Efforts by SMEs to obtain capital from banks often prove futile, mostly because they do not have collateral required by banks [2]. In the absence of collateral, potential funding entities require the SMEs to submit a business plan which is equivalent to a master budget in order to make a decision on whether or not to assist the business financially [28,31]. SMEs in the manufacturing industry can thus benefit significantly by preparing a master budget and using it to not only apply for start-up or additional capital but also to evaluate actual results against the budgets [18]. The budgeted balance sheet part of the master budget is very important to SMEs because it can highlight potentially serious financial problems when liabilities exceed assets or when current liabilities exceed current assets.

\section{Challenges faced in the utilisation of budgets}

Empirical research shows that challenges faced in the utilisation of budgets revolve around the criticisms slammed against budgets overtime. A forceful argument against budgets was presented by Hope and Fraser [32] who portrayed the tool as dysfunctional. Following this line of thought, other authors Neely et al. [33], Cardos [34] critiqued that budgets are considered expensive as they require time and other resources to prepare. It is a challenge to utilise budgets as they constrain responsiveness in unstable and unpredictable environments $[35,36]$ urge that the dynamics of the business environment call upon proactive utilisation of budgets to increase business' chances of success. Yet another challenge emanates from lack of sufficient data for forecasting more so because of inadequate bookkeeping skills among managers of small businesses.

Bournistov and Kaarboe report that utilisation of budgets is a challenge as budgets are rigid and reduce the managers' ability to take quick actions [37]. This rigidity leads to loss of business opportunities. Notwithstanding the aforementioned criticisms and challenges, $[34,35,38]$ accentuate that while problems exist with budgets and utilisation thereof, business organisations ought to work towards countering these problems rather than abandoning budgets altogether.

\section{Methodology}

A survey research method was employed to conduct this study. In a survey, the researcher administers a standard questionnaire to a selected sample of respondents from a population and, or conducts interviews to gather information on variables of interest. A survey was considered suitable for this study for a number of reasons which enabled the researcher to obtain information from 108 owners/managers of SMEs in the manufacturing industry of the Cape metropolis. These respondents have the relevant information or experience that bears on the problem being investigated [12]. The information could be analysed to extract patterns and to draw comparisons and conclusions Zikmund and Babin [39] about the use of budgets by SMEs in the manufacturing industry of the Cape metropolis. Moreover, this method was less expensive and a more convenient in a relatively short period of time [40].

\section{Population}

The target population for this study comprised SMEs in the manufacturing industry operating within the Cape metropolis. For the purpose of this study, SMEs refer to independent economic units which meet the following additional criteria: business entities employing between 51 to 200 or 250 employees. Within the SMEs in the manufacturing industry operating in the Cape metropolis, respondents comprised owners/managers as these are the rightful decision makers in the business entities.

\section{Sampling}

This study employed purposive sampling. The purposive sampling method enables the researcher to sample the respondents based on predetermined qualities [41]. Accordingly, a sample of SMEs in the manufacturing industry operating in the Cape metropolis was drawn based on the criteria outlined in the target population above. SMEs not operating in the manufacturing industry were excluded from the study. Micro enterprises in the manufacturing industry were equally excluded as they were considered too small to draw from or to utilise budgets $[30,40]$.

Purposive sampling was the most suitable sampling method for the following four reasons: firstly, given the researcher's limited time and financial constraints; secondly, the sample has the characteristics of the researcher's interests and the analysis of results is limited to the population under study $[41,42]$, thirdly, the lack of a comprehensive list of SMEs operating in the Cape metropolis rendered probabilistic sampling impracticable. For the reasons above, purposive sampling technique was deployed to distribute 120 questionnaires to the SMEs falling within division ten to division thirty three of the Standard Industrial Classification (SIC) of the manufacturing industry [43].

A questionnaire was the suitable instrument for this study because it reduces bias that might result from the personal characteristics of the researcher. It is easier to analyse data obtained from closed-ended questions than from open-ended questions. It is easier to code and statistically analyse data from questionnaires than from interviews. The questionnaire guaranteed anonymity and confidentiality; as the respondents were not requested to identify themselves. A questionnaire was suited to the study as it is commonly used to collect vital information about a population [39] which in this study comprised all SMEs in the manufacturing industry.

The questionnaire used closed questions. As closed questions provide for a set of responses from which a respondent has to select one or more than one response. Questions one and two were dichotomous questions which required a "Yes" or "No" answer and were used to divide the sample into two subclasses. Question three was a follow-up question and used Likert-scales to obtain further information.

The data was captured and analysed using the Statistical Package for Social Sciences (SPSS Version 24) software. It was advantageous to use this software because it has functions which assist with interpretation of statistical results and it facilitates creation of frequency tables, graphs and charts.

\section{Results and Discussion}

\section{Descriptive results on whether the respondents used budgets}

To determine the extent to which SMEs in the manufacturing industry used budgets, the researcher asked the following question:

Question 1: Does your business use budgets for managing business?

This question required a "Yes" or "No" answer. The purpose of this question was to eliminate the assumption that all SMEs in the sample used budgets. Respondents who indicated "Yes" were required to proceed to Question 2. 
Citation: Mwanza PS, Benedict HO (2018) Challenges in Utilising Budgets among SMES in the Manufacturing Sector Is the Cape Metropole. J Entrepren Organiz Manag 7: 222. doi: 10.4172/2169-026X.1000222

Page 4 of 6

As shown in Table 1, a majority of 76 respondents $(70.4 \%)$ indicated that they used budgets to manage their businesses while 32 respondents (29.6\%) indicated that they did not use budgets to manage their businesses. These results reveal that not all SMEs operating in the manufacturing industry in the Cape metropolis use budgets to manage their businesses.

\section{Descriptive results on whether respondents faced challenges when using budgets}

Question 2: Does your business face any challenges when using budgets?

This question required a "Yes" or "No" answer. The purpose of this question was to eliminate the assumption that all SMEs who used budgets faced challenges. The total number of respondents in this question is based on the 76 respondents who indicated in Question 1 that they use budgets (Table 1).

As presented in Table 2 above, $67.1 \%$ of the respondents who used budgets faced challenges in using budgets while $32.9 \%$ did not face challenges in using budgets.

\section{Descriptive results on challenges faced by respondents when using budgets}

To determine the challenges faced by SMEs in the manufacturing industry when using budgets, respondents who faced challenges when using budgets were then asked the following question:

Question 3: To what extent do you agree with the following statements about challenges faced by your business when using budgets?

The respondents were required to indicate the extent to which they agreed or disagreed about facing the stated challenges, choosing from strongly disagree, disagree, neutral, agree or strongly agree.

Responding to question 3 stated above, $78.4 \%$ of the respondents

\begin{tabular}{|c|c|c|c|}
\hline & Frequency & Percentage & Cumulative Percentage \\
\hline Yes & 76 & 70.4 & 70.4 \\
\hline No & 32 & 29.6 & 100.0 \\
\hline Total & 108 & 100.0 & \\
\hline
\end{tabular}

Table 1: Whether the business uses budgets

\begin{tabular}{|c|c|c|c|}
\hline & Frequency & Valid Percentage & Cumulative Percentage \\
\hline Yes & 51 & 67.1 & 67.1 \\
\hline No & 25 & 32.9 & 100.0 \\
\hline Total & 76 & 100.0 & \\
\hline
\end{tabular}

Table 2: Whether the business faced challenges when using budgets. agreed that they faced the challenge of lack of sufficient data for preparation of budgets while $74.5 \%$ agreed that they faced the challenge of budgets being expensive and time consuming. A lack of knowledge on how to prepare budgets was indicated as a challenge by $72.5 \%$ of the respondents. Similarly, $72.5 \%$ indicated that the business environment was too uncertain to use budgets. A lack of required resources such as computers was cited as a challenge by $70.6 \%$ of the respondents, similar to the challenge that unrealistic targets in the budgets lead to demotivation. The next most commonly cited challenge, at $66.7 \%$, is a lack of the necessary qualification and experience required to prepare and use budgets. Of the respondents, 43\%in this question cited the challenge that budgets caused inflexibility in decision-making, followed by $37.3 \%$ who cited the challenge that budgets do not always promote customer satisfaction. Only $23.5 \%$ indicated a lack of awareness about the importance of budgets as a challenge (Tables 3 and 4 ).

Results reveal that the respondents who used budgets faced various types of challenges. As indicated in Table 4 above, the standard deviation of more than one shows that the respondents did not agree on the challenges which were faced in the use of budgets.

The researcher henceforth discusses these results and attempts to suggest possible solutions to these challenges owing to which more and more SME owners/managers might avoid preparation and utilization of budgets for managing their businesses. Such a development would place these entities at a considerable disadvantage in the face of their more nimble competitors. These challenges may be overcome.

The challenge of lack of sufficient data for budget preparation was cited by $78.4 \%$ of the respondents. Historical data is instrumental as an input in the budget preparation process. Evidently information is a very important input in using budgets. Primarily, the bookkeeping and accounting records of the SMEs should be well maintained and function as a source of input data for budget preparation. SME owners/ managers can readily obtain this data from their bookkeeping records [18]. However, recent research has revealed that, lamentably SME owners/managers are not sufficiently skilled in financial accounting Fatoki [44] and that their bookkeeping skills must still be developed. The recommended training from these empirical studies should enable the owners/managers to use the accumulated bookkeeping records as input data into the budget preparation process. There is a need for SMEs to search for information internally from employees and externally from the industry, from the Department of Small Business Development and from periodic publications.

From the results, $74.5 \%$ indicated that budgets are too expensive and time consuming to prepare while $70.6 \%$ indicated that they lacked the required resources to prepare and use budgets for managing the businesses. These challenges are not new as they have been cited before

\begin{tabular}{|c|c|c|c|}
\hline & \multicolumn{3}{|c|}{ Percentage that agreed or disagreed about facing this challenge in using budgets } \\
\hline Type of challenge faced by the business in using budgets & Strongly Disagree/Disagree & Neutral & Agree/Strongly Agree \\
\hline A lack of sufficient data for budget preparation. & 15.7 & 5.9 & 78.4 \\
\hline Budgets are expensive and time consuming. & 21.6 & 3.9 & 74.5 \\
\hline A lack of knowledge on how to prepare budgets & 19.7 & 7.8 & 72.5 \\
\hline The business environment is too uncertain to use budgets. & 15.7 & 11.8 & 72.5 \\
\hline A lack of required resources such as computers. & 29.4 & 0 & 70.6 \\
\hline Unrealistic targets in the budgets lead to demotivation. & 17.6 & 11.8 & 70.6 \\
\hline A lack of the necessary qualifications and experience to prepare and use budgets. & 21.5 & 11.8 & 66.7 \\
\hline Budgets cause inflexibility in decision-making. & 33.4 & 23.5 & 43.1 \\
\hline Budgets do not always promote customer satisfaction. & 43.1 & 19.6 & 37.3 \\
\hline A lack of awareness on the importance of budgets. & 70.6 & 5.9 & 23.5 \\
\hline
\end{tabular}

Table 3: Type of challenge faced by the business in using budgets. 
Citation: Mwanza PS, Benedict HO (2018) Challenges in Utilising Budgets among SMES in the Manufacturing Sector Is the Cape Metropole. J Entrepren Organiz Manag 7: 222. doi: 10.4172/2169-026X.1000222

Page 5 of 6

\begin{tabular}{|c|c|c|c|}
\hline Type of challenge faced by the business in using budgets & $\begin{array}{l}\text { Percentage that agree to facing } \\
\text { the challenge }\end{array}$ & Mean $(n=76)$ & Standard deviation \\
\hline A lack of sufficient data for budget preparation. & 78.4 & 3.57 & 1.153 \\
\hline Budgets are expensive and time consuming. & 74.5 & 3.71 & 1.238 \\
\hline A lack of knowledge on how to prepare budgets & 72.5 & 2.35 & 1.146 \\
\hline The business environment is too uncertain to use budgets. & 72.5 & 2.88 & 1.107 \\
\hline A lack of required resources such as computers. & 70.6 & 3.71 & 1.026 \\
\hline Unrealistic targets in the budgets lead to demotivation. & 70.6 & 3.61 & 1.358 \\
\hline A lack of the necessary qualification and experience to prepare and use budgets. & 66.7 & 3.73 & 1.041 \\
\hline Budgets cause inflexibility in decision-making. & 43.1 & 3.78 & 1.270 \\
\hline Budgets do not always promote customer satisfaction. & 37.3 & 3.12 & 1.465 \\
\hline A lack of awareness about the importance of budgets. & 23.5 & 1.33 & 0.473 \\
\hline
\end{tabular}

Table 4: Statistical summary- challenge faced by the business in using budgets.

by critics of budgeting [32,33]. Utilization of budgets, like any other management tool, demands commitment of resource such as time, computers and manpower. The researcher considers that budgets are useful tools, the utilization of which may change the direction of business operations from failure to growth and sustainability. Such tools are worth investing in as the returns thereof outweigh these costs and inputs.

Unrealistic targets in the budget pose as a challenge to $70.6 \%$ of the respondents. Similarly, Hope and Fraser [32] criticised that using budgets causes antagonism, decreases job satisfaction and performance. According to Frow et al. [45] this challenge may be overcome by participatory budgeting. Under participatory budgeting, SME owners/managers promote participation of other staff members in the budgeting process thereby infusing creativity and innovation into the budget. Employees are more motivated to meet goals the setting of which they have participated in than the goals that have been imposed on them by the owners/managers. Besides, the researcher is of the opinion that while budgeted estimates could be far from reality, an estimated plan in the right direction is better than no plan at all.

To overcome the challenges of lack of knowledge (72.5\%), lack of necessary qualification and experience $(66.7 \%)$ and lack of awareness about the importance of budgets (23.5\%), entrepreneurial training should be used. In his research, Onduso [20] equally identified the challenge of lack of knowledge on setting goals of attainment among SMEs. To overcome this challenge, SMEs owners/managers have the option of engaging the services of accountants who help the businesses with financial reporting and planning. Literature from Fatoki [44], Kirsten and Fourie [26] has emphasised and called for training programmes to impart financial literacy and bookkeeping skills to SME owners/managers. SME owners/managers in the manufacturing industry of the Cape metropolis also need to acquire these critical skills. Furthermore, owners/managers can acquire budgeting skills through SME-tailored training initiatives planned and facilitated by the Department of Small Business Development (DSBD). As may be deduced from the analysis of the data on highest qualifications held by the respondents in this study, SMEs are managed by highly qualified entrepreneurs. These highly qualified entrepreneurs can succeed in acquiring the necessary skills to effectively utilise budgets for managing their businesses.

Finally, the last three challenges cited by the respondents in this question are that budgets do not always promote customer satisfaction (37.3\%), the business environment is too uncertain to use budgets $(72.5 \%)$ and that budgets cause inflexibility in decision-making (43.1\%). A study by De Waal [46] also reflects these findings; that the data in budgets is untrustworthy considering the rapid rate of change in both the internal and the external environment. According to De Waal [46], businesses are challenged by the highly competitive and turbulent business environment coupled with shorter product life cycles. Equally, Hope [47] advances that customer satisfaction and performance decrease due to lack of flexibility in adapting to change. To counter the challenges identified by De Waal [46] Hope [47], Frow et al. [45] proposed the use of continuous budgeting or flexible budgeting. Flexible budgeting allows SME owners/managers to continually adapt the goals in the budgets to the volatile environment. In this way, the business will respond to the changing environment, keep up with new developments and take hold of opportunities in the marketplace $[48,49]$. Flexible budgeting entails reviewing plans and allocation of business resources in order to achieve business objectives. The uncertain business environment should not deter SMEs in the manufacturing industry of the Cape metropolis from using budgets. To the contrary, these entities should be driven to use budgets all the more because the essence of planning is so that businesses survive the uncertain business environment. If the business environment were certain there would be no need for planning [50].

\section{Conclusion}

Most SMEs in the manufacturing industry of the Cape Metropolis use budgets for managing their businesses. The SMEs however face challenges when utilising budgets. Admittedly there are challenges that impede the utilization of budgets by businesses. Albeit, the researcher is of the notion that these challenges ought not to discourage owners/managers of SMEs in the manufacturing industry in the Cape metropolis from using budgets as deliberate actions that may be taken to alleviate these challenges. If utilization of budgets makes the difference between failure and success, SMEs in the manufacturing industry of the Cape metropolis need to employ these management tools even more aggressively despite the challenges. The objective to investigate the challenges faced by SMEs when using budgets was thus achieved.

\section{References}

1. South Africa Government (1996) Small Business Act No 102 of 1996, Pretoria Government Printers.

2. Shaku MD (2011) The gap in management accounting skills required by venture capital providers and those possessed by small and medium enterprises in the craft industry. University of South Africa, Pretoria.

3. Ngary C, Smit Y, Juan-Pierre B, Ukpere WI (2014) Financial Performance Measures and Business Objectives Attainment in Fast Food SMMEs in the Cape Metropolis: A preliminary Liability and Suitability analysis. Mediterranean Journal of Social Sciences 5: 909-921.

4. Herrington M, Kew J, Kew P (2009) Tracking Entrepreneurship in South Africa: A gem perspective. 
Citation: Mwanza PS, Benedict HO (2018) Challenges in Utilising Budgets among SMES in the Manufacturing Sector Is the Cape Metropole. J Entrepren Organiz Manag 7: 222. doi: 10.4172/2169-026X.1000222

5. Mmbengwa V, Ramukumba T, Groenewald J, Van Schalkwyk H, Gundidza $\mathrm{M}$, et al. (2011) Factors that influence the success and failure of land bank supported farming small, micro and medium enterprises (SMME) in South Africa. Journal of Development and Agricultural Economy 3: 35-47.

6. Lwiki T, Ojera PB, Mugend NG, Wachira VK (2013) The impact of inventory management practices on Financial Performance of Sugar Manufacturing firms in Kenya. International Journal of Business, Humanities and Technology 3: 75-85.

7. Berry PR (2011) Financial Planning and control systems: Essential tools to increase the survival rate of micro and small manufacturing enterprises in the Tswane Metropolitan area.

8. Bruwer JP, Abdurahman MR, Addinall J, Chandler E, Daniels N, et al. (2012) Utilisation of budgets in clothing small medium and micro enterprises (SMMEs) within the Cape Metropole. African Journal of Business Management 6: 7529 7532 .

9. Olosola A, Olowaseun $Y$ (2014) Influence of budgeting system on Entrepreneurial Business performance: perspective of Small business Owner in Lagos state Nigeria. Journal of Business and Management 16: 58-64.

10. Zimmerman JL (2014) Accounting for Decision Making and Control. 8th edition. McGraw Hill higher Education

11. Rao PN (2009) Manufacturing Technology. 3rd ed. Tata McGrawhill.

12. Matsoso ML, Benedict OH (2015) Critical success factors towards the implementation of total quality management in small medium enterprises: a comparative study of franchise and manufacturing businesses in Cape Town. Investment Management and Financial Innovations 12: 163-174.

13. State Enterprises Development Agency (2012) Analysis of the needs, state and performance of small and medium businesses in Agriculture, manufacturing, ICT and Tourism sector in South, Mthente: Research and consulting services.

14. Statistics South Africa (2013) Statistical Release P0211. Quarterly Labour Force Survey.

15. Mthabela TE (2015) Assessing the Causal Failures of Emerging Manufacturing SMEs in Johannesburg. University of the Witwatersrand, Johannesburg.

16. Statistics South Africa (2015) Economy.

17. Needles BE, Crosson SV (2013) Managerial accounting. Cengage Learning

18. Worrel D (2014) Entrepreneur's guide to financial statements. Santa Barbara: Praeger.

19. Lohr M (2012) Specifities of managerial accounting at SMEs: Case studies from the German Industrial Sector. Journal of Small Business and Entrepreneurship 25: 35-55.

20. Onduso EO (2013) The effect of budgets on financial performance of manufacturing companies in Nairobi County. University of Nairobi, Kenya.

21. Drury C (2015) Management and Cost Accounting. 9th ed. Cengage Learning. United Kingdom.

22. Groover MP (2010) Fundametals of Modern Manufacturing: materials, processes and systems. 4th edition. John Wiley and Sons Inc.

23. Abanis T, Sunday A, Burani A, Eliabu B (2013) Financial management practices in small and medium enterprises in selected districts in Western Uganda. Research Journal of Finance and Accounting 4: 29-42.

24. South Africa (1997) Basic Conditions of Employment

25. Mutanda M, De Beer M, Myers GT (2014) The Perception of Small \& Micro enterprises in the City of Durban Central Business District (CBD) (KZN) towards financial planning. Mediterranean Journal of Social Sciences 5: 153-163.

26. Kirsten CL, Fourie JR (2012) The accounting profession's role in financial management skills development of small businesses. Journal of Economic and Financial Sciences 5: 459-480.

27. Kaplan RS, Atkinson AA (2015) Advanced Management Accounting. 4th ed Pearson Education.
28. Maseko N, Manyani O (2011) Accounting practices of SMEs in Zimbabwe: An investigative study of record-keeping for performance measurement (A case study of Bindura). Journal of Accounting and Taxation 3: 158-161.

29. Bruwer JP, Kemp A, Bowman A, Blom B, Visser C et al. (2015) The Usefulness of Cash Budgets in Micro, Very Small and Small Retail Enterprises Operating in the Cape Metropolis. Expert Journal of Business Management 3: 1-12.

30. Alleyne P, Weekes-Marshall D (2011) An Explorative study of Managemen Accounting Practices in Manufacturing Companies in Barbados. International Journal of Business \& Social Sciences 2: 35-43.

31. Mugobo VV, Ukpere WI (2012) Rural entrepreneurship in the Western Cape: Challenges and opportunities. African Journal of Business Management 6 : 827-836.

32. Hope J, Fraser R (2003) Who needs budgets? Harvard Business Review 81 108-115.

33. Neely A, Bourne M, Adams C (2003) Better budgeting or beyond budgeting? Measuring Business Excellence 7: 22-28.

34. Cardos IR (2014) New trends in budgeting-A literature review. Practica Application of Science 2: 483-490.

35. Libby T, Lindsay RM (2010) Beyond budgeting reconsidered? A survey of North-American budgeting practice. Management Accounting Research 21 : 56-75.

36. Zeller TL, Metzger LM (2013) Goodbye Traditional Budgeting, Hello Rolling Forecast: Has The Time Come? American Journal of Business Education 6 : 299-310.

37. Bournistov A, Kaarboe K (2013) From comfort zones: A field study of two multinational companies applying "beyond budgeting" ideas. Management Accounting Research 24: 196-211.

38. Hanninen V (2013) Budgeting at Crossroads: The Viability of Traditional budgeting - A case study. Aalto University.

39. Zikmund WG, Babin BJ (2012) Essentials of marketing research. Cengage Learning.

40. Maduekwe CC (2015) The usage of management accounting tools by smal and medium enterprises in Cape Metropole, South Africa. Cape Peninsula University of Technology, Cape Town.

41. Tongco MDC (2007) Purposive sampling as a tool for informant selection. Ethnobotany Research \& Applications 5: 147-158.

42. Myers JL, Well A, Lorch RF (2010) Research design and statistical analysis Routledge.

43. Statistics South Africa (2011) Census.

44. Fatoki O (2014) The Causes of the Failure of New Small and Medium Enterprises in South Africa. Mediterranean Journal of Social Sciences.

45. Frow N, Marginson D, Ogden S (2010) Continuous budgeting: Reconciling budget flexibility with budget control. Accounting, Organisations and Society 35: $444-461$

46. De Waal AA (2005) Is your organisation ready for beyond budgeting? Measuring Business Excellence 9: 56-67.

47. Hope J (2006) Reinventing the CFO: How Financial Managers Can Transform Their Roles and Add Greater Value. Harvard Business School Press.

48. https://pdfs.semanticscholar.org/73b7/18e508fa943dfb22a9cb5fb17f888239a d0e.pdf

49. Kotler P, Armstrong G (2011) Principles of Marketing. 14th ed. Pearson Higher Education.

50. South Africa Department of Trade and Industry (2013) Youth Enterprise development strategy 2013-2023. Pretoria: Government Printer. 